\title{
Feasibility Trial of a Brief Cannabis Use Intervention Delivered by Telephone
}

\author{
Peter Gates ${ }^{1}$ and Jan Copeland ${ }^{1,2 *}$ \\ 1National Cannabis Prevention and Information Centre, UNSW Medicine, Australia \\ 2Cannabis Information and Support, Australia
}

Submission: April 21, 2017; Published: April 28, 2017

*Corresponding author: Jan Copeland, Cannabis Information and Support, P0 Box 257, St Ives, NSW 2075, Australia, Tel: +61 414385153;

Email: Profj@CISCopeland.com Website: http://www.cannabissuport.com.au

Abstract

Background: We tested the feasibility and efficacy of a brief single-session cannabis intervention delivered by the Cannabis Information and Helpline (CIH) in Australia.

Methods: Callers were invited for random allocation to receive the telephone intervention $(\mathrm{n}=18)$ or a self-help workbook control condition $(n=20)$. Recruitment was a challenge as callers displayed a lack of interest in the brief treatment. Following randomisation, participants were followed up at three months from baseline with half the sample lost to follow-up.

Results: The small final sample ( $\mathrm{n}=19)$ was insufficient for adequately powered analysis and no significant differences between group differences were found.

Conclusion: These findings were in contrast to the previous success of a more intensive four-session intervention delivered by the $\mathrm{CIH}$ and imply that despite single sessions being common in all outpatient counselling settings, it does not appear to be sufficiently engaging for recruitment to a telephone-based cannabis treatment.

Keywords: Cannabis; Brief treatment; CBT; Telephone counseling; Helpline

Abbreviations: SDS: Severity of Dependence Scale; CIH: Cannabis Information and Helpline; TLFB: Time-Line Follow Back; CPQ: Cannabis Problems Questionnaire

\section{Introduction}

Cannabis remains to be the most commonly used illicit drug throughout the world [1]. Approximately one in six of those who use cannabis during adolescence and one in two of daily cannabis users are at risk of becoming dependent on cannabis use $[2,3]$. Despite many negative psychiatric and social consequences experienced by those dependent on cannabis use $[4,5]$ many perceive themselves as unable to quit, [6] and the majority do not seek professional treatment [7]. Nevertheless, the prevalence of cannabis users has led to a doubling in rates of cannabis treatment from 2000 to 2013 in Australia, with the current rate fluctuating between $22 \%$ and $24 \%$ since 2008 [8]. Such demand on traditional face-to-face treatments has prompted focus on novel treatment options which can utilise technology to provide cannabis treatment on a grander scale [9].

The use of the telephone to provide treatment to a wider set of treatment seekers for non-tobacco substance use is a new field with scant research [10]. Notably, telephone-based treatments for cannabis use have only been investigated in two previous trials [11,12]. In the first trial, a single-session intervention based on Motivational Interviewing was first trialled in Brazil [13]. This trial recruited 1,744 adults (74\% male, mean age of 25 years) from callers to a Brazilian cannabis-specific helpline. Interested callers were randomly allocated to receive either a single 20 minute MET+CBT-based session with self-help materials delivered or the self-help materials alone. A large loss to follow-up was reported across the six-month follow-up period with less than one third (30\%) completing the final follow-up at six months $(n=524)$. The authors reported that those who received the telephone intervention were $160 \%$ more likely to report abstinence at six months.

This second trial was our own four-session telephone intervention based on Motivational Interviewing combined with Cognitive Behavioral Therapy, conducted in Australia [11]. 
In this trial, 160 adult participants (62\% male, mean age of 36 years) were randomly allocated to receive a four session (each 60 minutes, delivered once a week) MET+CBT intervention with self-help materials immediately or in three months (delayed treatment control). The participants were followed up at treatment end and at three months from baseline. Approximately one third (31\%) of participants were lost to follow-up (final sample; $\mathrm{n}=110$ ). In this trial intervention participants reported greater reductions in dependence symptoms $(d=0.9)$ and related problems $(d=0.5)$ compared with control participants at both follow-up points. This difference was largely mediated by the ability of treatment to influence greater confidence to quit.

An additional finding from this second trial was that treatment completion was not significantly associated with treatment outcomes. In fact, those who received even a single session of the intervention reported comparable improvements to those who received the full four sessions. It was thus of interest to determine the feasibility of a potentially more cost-effective single-session intervention for cannabis use disorder. In addition, there is a growing focus on so-called 'brief interventions' which are time-limited with a particular focus on the individual treatment seeker and their current situation $[14,15]$. Finally, the day-to-day services of drug and alcohol helplines typically resemble a brief intervention [16], although the efficacy of this service remains largely untested.

\section{Method}

\section{Participants}

A total of 1213 genuine calls (not including hoax/nuisance calls or internal calls) requesting information or counselling regarding cannabis-related concerns were received by the Cannabis Information and Helpline (CIH) during the 10-month participant recruitment phase from December 2015 to September 2016 (Figure 1). Of those, 14.1\% ( $n=171)$ were informed about the treatment trial. Reasons for not informing the caller of the trial included that the call was regarding a third party (39.3\%), the caller had already quit cannabis use $(15.4 \%)$, the caller was too distressed at the time of call $(12.9 \%)$, the call ended too soon $(5.2 \%)$, or that it was otherwise inappropriate (24.6\%). In addition, 33 callers were not informed of the trial as they did not meet the trial inclusion criteria. A total of one third $(32.7 \% ; n=56)$ of those informed of the trial were interested and passed on their contact details. The most common reasons for refusal were a lack of interest in the treatment (70.4\%), that the caller would call back after considering the offer (17.4\%), or for other reasons such as concern for confidentiality (12.2\%).

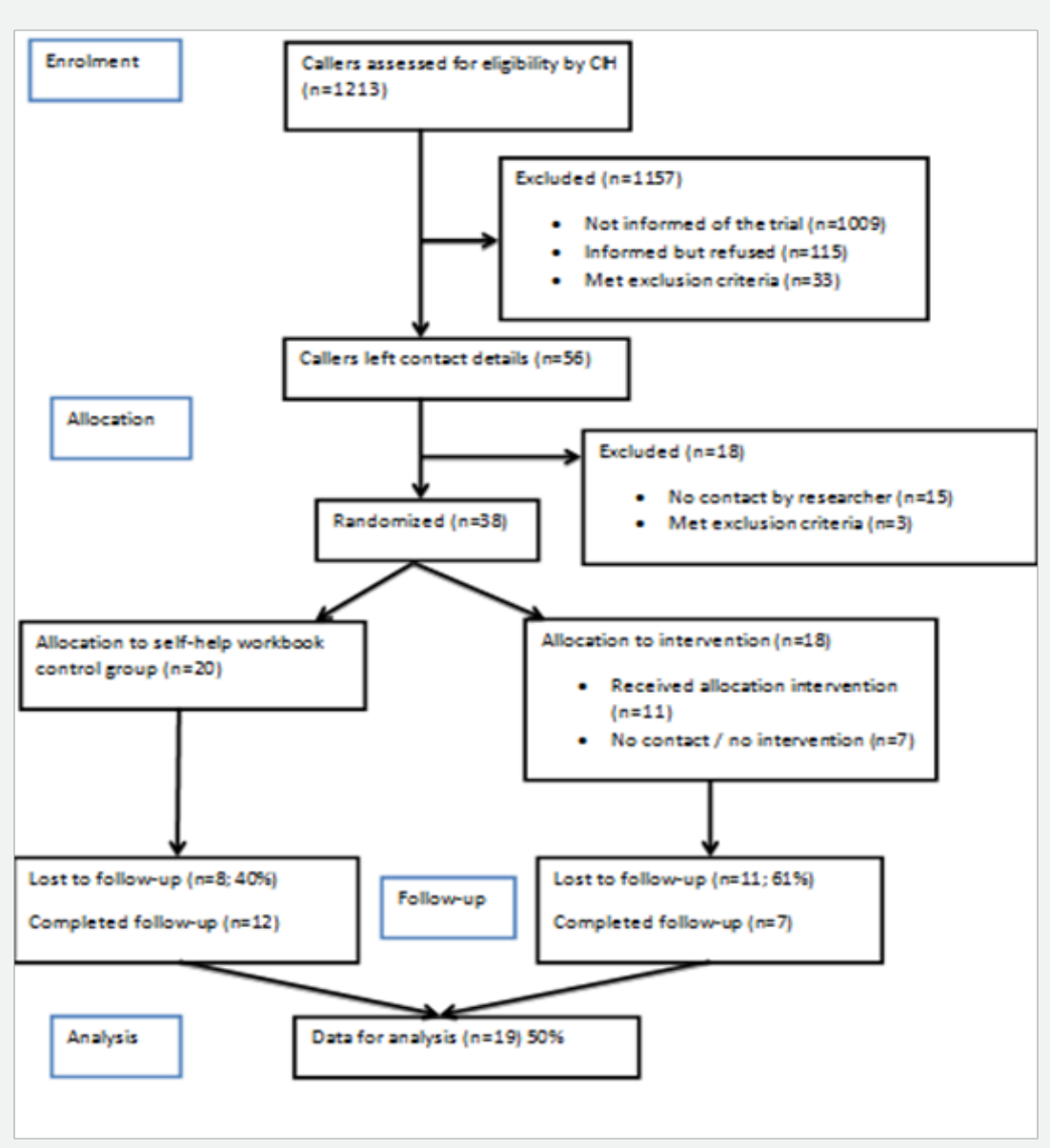

Figure 1: Participant flow diagram. 
Approximately two thirds $(67.9 \% ; n=38)$ of those who provided contact information were contacted successfully by the researcher (PG) and completed the baseline interview, while three were found to be ineligible. Eligible participants were any individual who: was at least 18 years of age; had used cannabis within the past month (4 excluded); was not receiving concurrent treatment or medication for cannabis use (23 excluded); did not identify as being dependent on other illicit drugs ( 9 excluded); and had not been hospitalized for a mental health condition related to cannabis use within 12 months.

\section{Research Design}

Simple one-to-one, non-stratified, random assignment was used to assign eligible participants to one of two conditions:

(i) the intervention condition $(n=18 ; 47.4 \%)$ or

(ii) the control condition $(n=20 ; 52.6 \%)$. Both conditions included a baseline interview and a single follow-up interview at 12 weeks post-baseline conducted via telephone by the researcher $(\mathrm{PG})$.

\section{Procedure}

Following approval from the Human Research Ethics Committee at the University of New South Wales, CIH staffs were trained to deliver the intervention (details below). Recruitment was conducted solely by $\mathrm{CIH}$ counsellors who screened calls for suitability. Interested callers provided verbal consent once informed about the trial and the possibility of being allocated to the treatment or control groups. Project CAHL was advertised using Facebook Advertising Platform and appeared on the newsfeed of Facebook users aged 18 years or over who had listed location within Australia. The advertisement had a click through rate of $1.08 \%$ and reached 11,758 individuals who were forwarded to a page detailing the study with the CIH telephone number. In addition, health providers who made contact with the National Cannabis Prevention and Information Centre during the recruitment period were asked to inform their own client base about the trial.

\section{Baseline Assessment}

Participants were contacted by telephone by the researcher (PG) to complete the baseline assessment within one week of their call to the CIH. Up to two contact attempts were made per day across five business days. Any individual who could not be contacted using this strategy was considered 'not contactable' (Figure 1).

The assessment consisted of a structured interview. Demographic details were collected utilizing the National Minimum Data Set [17]. In addition, variables associated with indices of relative socio-economic advantage or disadvantage were collected (participant income and years of education). Details regarding participants' cannabis use were collected utilizing validated measures including a 28-day Time-Line Follow Back (TLFB) interview [18], the Severity of Dependence Scale
(SDS) [19] and the Cannabis Problems Questionnaire (CPQ) [20]. Participants identified with one of the five stages of change [20], and indicated their confidence to reduce/maintain abstinence from 0 (not at all confident) to 10 (extremely confident) based on Stephens and colleagues' self-efficacy index [21].

Levels of psychological distress were measured utilising the Kessler-10 psychological distress scale [22]. Finally, participants were asked to detail how many days in the previous 90 days they had used alcohol, tobacco or any illicit drug. The TLFB interview method was not utilized to assess other substances to promote the brevity of the assessment. Given the importance of promoting motivation to change by providing personalized feedback [23], the data which was collected in the initial assessment was transcribed to a personal feedback report and transferred to the $\mathrm{CIH}$ for participant discussion during the first telephone intervention session.

\section{Follow-up Assessment}

The follow-up assessment was conducted at 12 weeks after the baseline interview by the researcher (PG). The protocol for contacting participants at baseline was replicated. Participants were reimbursed with $\$ A U 30$ for their time upon completing the follow-up assessment.

\section{Participant Group Conditions}

\section{The telephone intervention condition}

The CAHL intervention consisted of a single, 60-minute counselling session, modelled to be a condensed version of the previously tested four session intervention and similar to the single session used in a previous trial of a face to face intervention $[11,24]$. Briefly, the session began with motivational interviewing techniques to enhance and solidify readiness to change. This included feedback on cannabis use and severity of dependence. Participants were encouraged to schedule a reduction in cannabis use by one-third per week (a 'cold turkey' approach was allowed, but not advised). Finally, the session focussed on enhancing the participants' behavioural skill sets to cope with, and/or avoid, their identified triggers. The three $\mathrm{CIH}$ counsellors who delivered the intervention were trained utilising two seven-hour workshops on intervention delivery; review of audio-taped role-plays; and received a treatment manual. The three counsellors had at least one year's telephone counselling experience and tertiary counselling qualifications.

\section{The self-help workbook control condition}

Directly following baseline assessment, participants were allocated randomly to the two trial conditions. Those allocated to the self-help workbook control group were mailed the Quitting Cannabis Workbook [25] with no further instruction.

\section{Data Analysis}

Analyses were conducted using IBM SPSS Statistics version 23. The primary outcome measures were: frequency and quantity of cannabis use and percentage days of abstinence (as 


\section{Global Journal of Addiction \& Rehabilitation Medicine}

measured by the TLFB); cannabis dependence (as measured by the SDS); and problems relating to cannabis use (as measured by the CPQ). The secondary outcome measures included other drug use (measured by 90-day frequency) and psychological distress (K-10). Given the small sample size, differences in baseline outcome variables and participant demographics between participant groups, those who dropped out or were followed up, and those allocated to the telephone intervention group who did or did not receive the intervention were assessed using two-tailed matched pair t-test giving $83 \%$ power (based on moderate power achieved in our previous trial of a four session intervention [11]). Similarly, group differences between the telephone intervention and self-help control on change in treatment outcomes from baseline to follow up were analysed using paired sample t-test.

Results

\section{Participants}

Table 1: Participant demographic and substance use information at baseline.

\begin{tabular}{|c|c|c|c|c|}
\hline & $\begin{array}{l}\text { Control }(n=20) \\
\text { Mean }(S D) / \%\end{array}$ & $\begin{array}{c}\text { Intervention }(\mathrm{n}=18) \\
\text { Mean (SD) / \% }\end{array}$ & $\begin{array}{c}\text { Total }(n=38) \\
\text { Mean (SD) / \% }\end{array}$ & Btw. Grp. Diff. \\
\hline Sex & & & & $\mathrm{P}=0.946$ \\
\hline Male & 60.0 & 61.1 & 60.5 & \\
\hline Age (in years) & $26.5(1.9)$ & $28.1(2.1)$ & $27.3(8.5)$ & $\mathrm{P}=0.593$ \\
\hline $\begin{array}{l}\text { Age at first cannabis use } \\
\text { (in years) }\end{array}$ & $15.3(0.6)$ & $15.2(0.5)$ & $15.2(2.4)$ & $\mathrm{P}=0.916$ \\
\hline $\begin{array}{l}\text { Age at first regular } \\
\text { cannabis use (in years) }\end{array}$ & $17.8(3.6)$ & $17.3(2.4)$ & $17.6(3.1)$ & $P=0.666$ \\
\hline Employed (full/part time) & 65.0 & 66.7 & 65.8 & $\mathrm{P}=0.917$ \\
\hline Education (in years) & $12.8(2.8)$ & $13.5(2.2)$ & $13.1(2.5)$ & $\mathrm{P}=0.386$ \\
\hline \multicolumn{5}{|l|}{ Stage of change } \\
\hline Pre-contemplation & 0.0 & 0.0 & 0.0 & \\
\hline Contemplation & 35.0 & 27.8 & 31.6 & $\mathrm{P}=0.643$ \\
\hline Preparation & 35.0 & 50.0 & 42.1 & $\mathrm{P}=0.363$ \\
\hline Action & 15.0 & 11.1 & 13.2 & $\mathrm{P}=0.732$ \\
\hline Maintenance & 15.0 & 11.1 & 13.2 & $\mathrm{P}=0.732$ \\
\hline Confidence to quit (/10) & $5.7(2.4)$ & $6.1(2.7)$ & $5.9(2.5)$ & $\mathrm{P}=0.671$ \\
\hline $\begin{array}{l}\text { Days of cannabis use } \\
\text { (TLFB, past } 28 \text { days) }\end{array}$ & $26.0(2.5)$ & $23.9(6.1)$ & $25.0(4.6)$ & $\mathrm{P}=0.173$ \\
\hline $\begin{array}{l}\text { Number of cones (TLFB, } \\
\text { past } 28 \text { days) }\end{array}$ & $333.6(253.9)$ & $394.9(387.4)$ & $362.6(321.0)$ & $\mathrm{P}=0.563$ \\
\hline $\begin{array}{l}\text { Severity of dependence } \\
\text { (SDS) }\end{array}$ & $7.0(3.6)$ & $11.2(9.1)$ & $9.0(7.0)$ & $\mathrm{P}=0.057$ \\
\hline Cannabis problems (CPQ) & $9.1(4.0)$ & $9.9(4.4)$ & $9.5(4.1)$ & $\mathrm{P}=0.537$ \\
\hline Psychiatric distress (K10) & $23.9(6.5)$ & $29.3(13.0)$ & $26.4(10.3)$ & $\mathrm{P}=0.111$ \\
\hline $\begin{array}{l}\text { Alcohol frequency (past } \\
90 \text { days) }\end{array}$ & $25.3(24.3)$ & $19.1(25.2)$ & $22.3(24.6)$ & $\mathrm{P}=0.446$ \\
\hline $\begin{array}{l}\text { Tobacco frequency (past } \\
90 \text { days) }\end{array}$ & $58.2(39.5)$ & $47.8(41.3)$ & $53.3(40.2)$ & $\mathrm{P}=0.434$ \\
\hline $\begin{array}{l}\text { Other illicit drug use (past } \\
90 \text { days) }\end{array}$ & 3.8 (12.4) & $2.9(7.4)$ & $3.4(10.2)$ & $\mathrm{P}=0.800$ \\
\hline
\end{tabular}

(Table 1) depicts baseline demographic and substance use information for the 38 randomly allocated participants. Participants reported regular cannabis use (defined as 'at least weekly') for an average of 8.0 years $(S D=6.8)$ prior to the baseline interview. At baseline, $89.5 \%$ of participants were probably cannabis-dependent ( $\geq 3$ on the SDS [26]). Less than one quarter $(22.2 \%$; $=4)$ of the participants reported seeking any concurrent treatment at the follow-up assessment (this included one participant seeing their GP, one seeing a mental health counsellor and two participants visited their regular counsellor). As an artefact of trial inclusion criteria, any recent use of illicit drugs other than cannabis was infrequent with the exception of tobacco use. The majority of participants demonstrated indicators of a mild (23.7\%), moderate $(26.3 \%)$ or severe $(26.3 \%)$ mental health disorder at baseline according to Kessler 10 cut-offs [27]. 


\section{Global Journal of Addiction \& Rehabilitation Medicine}

\section{Treatment and trial retention}

Overall, $50 \%$ of participants $(n=19)$ did not complete the 12 week follow-up interview. Confidence in quitting (score out of 10) was the only baseline variable associated with this drop out, with those with greater initial confidence more likely to drop out (4.8 compared to $6.9 ; \mathrm{t}=2.879, \mathrm{df}=36, \mathrm{P}=0.007$ ). In addition, several participants who were randomized into the intervention condition were not contactable by the counsellors $(n=7)$, leaving only 11 treatment initiators. No significant difference on baseline variables was found between those participants who could not be contacted and those who initiated the intervention. All participants allocated to the Workbook condition reported using the Workbook at follow-up interview.

\section{Group differences in treatment outcomes}

Both participant groups showed improvements on all measures of cannabis use outcomes between the baseline and 12-week follow-up interview with one exception. Those receiving the Workbook reported less confidence to quit at follow-up interview. Results from the follow up interview and change scores from baseline to follow-up are presented in (Table 2). No significant between group differences were found on any treatment outcome. At follow up, $36.8 \%$ of the sample showed a level of psychological distress indicative of a need for review with specialist referral considered [27].

Table 2: Treatment outcomes at 12 week follow-up.

\begin{tabular}{|c|c|c|c|c|c|}
\hline Outcome & Control FU & $\begin{array}{c}\text { Control } \\
\text { change score }\end{array}$ & Intervention FU & $\begin{array}{c}\text { Intervention change } \\
\text { score }\end{array}$ & $\begin{array}{c}\text { Btw. Group diff. in } \\
\text { change }\end{array}$ \\
\hline Confidence to quit & $6.3(1.9)$ & $-0.1(3.4)$ & $6.6(2.8)$ & $1.7(4.7)$ & $\mathrm{P}=0.570$ \\
\hline Days of cannabis use & $15.7(11.7)$ & $10.6(11.0)^{*}$ & $16.6(10.5)$ & $9.1(8.5)^{*}$ & $\mathrm{P}=0.442$ \\
\hline Number of cones & $150.1(192.0)$ & $170.1(216.3)^{*}$ & $162.9(169.0)$ & $281.3(365.8)$ & $\mathrm{P}=0.413$ \\
\hline SDS & $4.1(2.5)$ & $2.3(3.1)^{*}$ & $6.0(4.8)$ & $5.3(4.0)^{*}$ & $\mathrm{P}=0.091$ \\
\hline CPQ & $5.6(4.4)$ & $3.1(4.9)$ & $6.1(2.3)$ & $4.1(3.0)^{*}$ & $\mathrm{P}=0.612$ \\
\hline K-10 & $24.1(13.5)$ & $0.4(12.2)$ & $22.1(7.3)$ & $10.9(15.7)$ & $\mathrm{P}=0.124$ \\
\hline Alcohol use & $20.8(23.7)$ & $2.4(16.2)$ & $9.0(9.2)$ & $9.3(9.4)^{*}$ & $\mathrm{P}=0.321$ \\
\hline Tobacco use & $40.8(43.4)$ & $15.2(34.1)$ & $24.7(34.3)$ & $1.0(19.6)$ & $\mathrm{P}=0.331$ \\
\hline Other illicit drug use & $1.0(1.7)$ & $4.6(15.7)$ & $1.1(1.9)$ & $3.9(10.3)$ & $\mathrm{P}=0.914$ \\
\hline
\end{tabular}

${ }^{*} P<0.05$ Significant difference between baseline and follow-up

\section{Discussion}

The present study was designed to test the feasibility and efficacy of a brief single-session cannabis use intervention delivered by telephone. Contrary to initial expectations, the intervention was not well received by callers to the Cannabis Information Helpline and loss to follow-up among those who did join the trial was a concern. This major finding stood in stark contrast to the successes of our previous four-session telephone intervention delivered by the same Helpline [11]. In addition, no significant group differences on any treatment outcome were noted between those who received the telephone intervention and those who received a self-help Workbook only. However, the small sample size compromised the statistical power to detect any such difference.

The lack of interest for the intervention trial displayed by callers to the Helpline was prominent, however; this may be explained by the usual operations of the service. That is, as the counsellors received calls for assistance they were not instructed to minimise any initial attempts to assist the caller before mentioning the trial. As such, many callers who may have been interested in a brief intervention prior to calling may have lost this interest after first receiving the brief contact with the Helpline. Indeed, the usual operation of the service is to provide brief counselling and the majority of callers find this satisfying [28]. In addition, it may be that callers seeking cannabis treatment were instead interested in a more intensive intervention. While this explanation goes against previous work describing an interest in brief treatment among cannabis users calling a Helpline in Brazil [12], it is in line with the finding that more intensive cannabis interventions are more likely to be effective [29].

Some limitations should be considered when interpreting these results. First, blinding procedures were not utilized due to difficulties inherent to non-pharmacological trials [30], as such, particular attention was paid to randomization procedures and the choice of validated outcome measures. Secondly, given the nature of the telephone intervention (participants were located throughout Australia) biomedical validation data could not be collected. Notably, the collection of such data is not recommended for telephone trials [31]. Finally, the use of a minimally active control condition may have diminished the telephone treatment effect due to its own brevity.

In summary, in contrast to the work of Fernandes and colleagues in Brazil [12], the results of this trial did not support the feasibility of a single-session telephone-based treatment for cannabis use problems in Australia. However, the benefits of a more intensive telephone-based intervention should not be overlooked. That is, such interventions can be delivered over 
wide areas where other services are limited (without face-toface interaction), and to those who might prefer the anonymity of such an intervention.

\section{Funding}

The authors received financial support from the Australian Government Department of Health.

\section{References}

1. European Monitoring Centre for Drugs and Drug Addiction (EMCDDA) European Drug Report 2016: Trends and developments. Luxembourg: EMCDDA 2016.

2. Anthony JC (2006) The epidemiology of cannabis dependence. Cannabis Dependence: Its Nature, Consequences and Treatment. Cambridge: Cambridge University Press.

3. van der Pol P, Liebregts N, de Graaf R, Korf DJ, van den Brink W, et al. (2013) Predicting the transition from frequent cannabis use to cannabis dependence: a three-year prospective study. Drug Alcohol Depend 133(2): 352-359.

4. Budney AJ, Novy PL, Hughes JR (1999) Marijuana withdrawal among adults seeking treatment for marijuana dependence. Addiction 94(9): 1311-1322.

5. Stephens RS, Roffman RA, Simpson EE (1993) Adult marijuana users seeking treatment. J Consult Clin Psychol 61(6): 1100-1104.

6. Copeland J, Swift W, Rees V (2001) Clinical profile of participants in a brief intervention program for cannabis use disorder. J Subst Abuse Treat 20(1): 45-52.

7. Teesson M, Slade T, Swift W, Mills K, Memedovic S, et al. (2012) Prevalence, correlates and comorbidity of DSM-IV Cannabis Use and Cannabis Use Disorders in Australia. Australian \& New Zealand Journal of Psychiatry 46(12): 1182-1192.

8. Australian Institute of Health and Welfare (AIHW) (2014) National Drug Strategy Household Survey detailed report 2013. Drug Statistics Series.

9. Rooke SE, Gates PJ, Norberg MM, Copeland J (2014) Applying technology to the treatment of cannabis use disorder: comparing telephone versus Internet delivery using data from two completed trials. J Subst Abuse Treat 46: 78-84.

10. Gates P, Albertella L (2016) The effectiveness of telephone counselling in the treatment of illicit drug and alcohol use concerns. Journal of Telemedicine and Telecare 22(2): 67-85.

11. Gates PJ, Norberg MM, Copeland J, Digiusto E (2012) Randomized controlled trial of a novel cannabis use intervention delivered by telephone. Addiction 107(12): 2149-2158.

12. Fernandes S, Ferigolo M, Benchaya MC, Moreira TdC, Pierozan PS, et al. (2010) Brief motivational intervention and telemedicine: A new perspective of treatment to marijuana users. Addictive Behaviors 35(8): 750-755.

13. Fiorentine R (1999) After drug treatment: are 12-step programs effective in maintaining abstinence? Am J Drug Alcohol Abuse 25(1): 93-116.
14. Miller W, Rollnick S (2003) Motivational interviewing: Preparing people for change. Journal for Healthcare Quality 25: 46.

15. Gates P (2015) The effectiveness of helplines for the treatment of alcohol and illicit substance use. J Telemed Telecare 21(1): 18-28.

16. Conroy JCA (2001) Australian National Minimum Data Set for Clients of Alcohol and Other Drug Treatment Services: findings of the national pilot and developments in implementation. Drug and Alcohol Review 20: 295-298.

17. Sobell LC, Sobell MB, Leo GI, Cancilla A (1988) Reliability of a timeline method: assessing normal drinkers' reports of recent drinking and a comparative evaluation across several populations. Br J Addict 83(4): 393-402.

18. Gossop M, Griffiths P, Powis B, Strang J (1992) Severity of dependence and route of administration of heroin, cocaine and amphetamines. $\mathrm{Br} J$ Addict 87(11): 1527-1536.

19. Copeland J, Gilmour S, Gates P, Swift W (2005) The Cannabis Problems Questionnaire: factor structure, reliability, and validity. Drug Alcohol Depend 80(3): 313-319.

20. DiClemente CC, Schlundt D, Gemmell L (2004) Readiness and stages of change in addiction treatment. Am J Addict 13: 103-119.

21. Stephens RS, Wertz JS, Roffman RA (1995) Self-efficacy and marijuana cessation: a construct validity analysis. J Consult Clin Psychol 63(6): 1022-1031.

22. Kessler RC, Mroczek DK (1994) Final versions of our non-specific psychological distress scale. Ann Arbor: Ann Arbor Mi.

23. Miller WR, Rollnick S (2002) Motivational Interviewing: Preparing People for Change. ( $2^{\text {nd }}$ edn.), New York: Guilford Press.

24. Copeland J, Swift W, Roffman R, Stephens R (2001) A randomized controlled trial of brief cognitive-behavioral interventions for cannabis use disorder. J Subst Abuse Treat 21(2): 55-64.

25. National Cannabis Prevention and Information Centre: Quitting Cannabis Workbook.

26. Swift W, Copeland J, Hall W (1998) Choosing a diagnostic cut-off for cannabis dependence. Addiction 93(11): 1681-1692.

27. Andrews G, Slade T (2001) Interpreting scores on the Kessler Psychological Distress Scale (k10). Australian and New Zealand Journal of Public Health 25(6): 494-497.

28. Gates P, Copel J, Norberg M, Digiusto E (2011) Caller satisfaction with the Cannabis Information and Helpline. J Telemed Telecare 17(2): 9398.

29. Gates PJ, Sabioni P, Copeland J, Le Foll B, Gowing L (2016) Psychosocial interventions for cannabis use disorder. Cochrane Database Syst Rev.

30. Boutron I, Tubach F, Giraudeau B, Ravaud P (2004) Blinding was judged more difficult to achieve and maintain in nonpharmacologic than pharmacologic trials. J Clin Epidemiol 57(6): 543-550.

31. SRNT Subcommittee (2002) Biomedical Verification: Biochemical verification of tobacco use and cessation. Nicotine Tob Res 4(2): 149159. 
Your next submission with Juniper Publishers will reach you the below assets

- Quality Editorial service

- Swift Peer Review

- Reprints availability

- E-prints Service

- Manuscript Podcast for convenient understanding

- Global attainment for your research

- Manuscript accessibility in different formats

( Pdf, E-pub, Full Text, Audio)

- Unceasing customer service

Track the below URL for one-step submission https://juniperpublishers.com/online-submission.php 